\title{
Seborrheic Keratosis: A Rare Clinical Appearance
}

\section{A Darjani, A Ramezanpour}

\section{Citation}

A Darjani, A Ramezanpour. Seborrheic Keratosis: A Rare Clinical Appearance. The Internet Journal of Dermatology. 2001 Volume 1 Number 2.

\section{DOI: $\underline{10.5580 / 994}$}

\section{Abstract}

A variety of clinical appearance of Seborrheic Keratosis have been already reported. We report the case of a 16-year-old woman who presented with itchy brownish papules on the right side of her chest with dermatomal distribution for 2 years. Diagnosis of the dermatosis was histologically evident. It seems that linear and dermatomal Seborrheic Keratosis is a new clinical variant.

\section{CASE REPORT}

A 16-year-old woman presented with a 2 -year history of itchy brownish papules localized on the right side of chest. (Fig. 1,2) It began whit dark brownish macules and patches on the right side of lower chest near to midline and gradually change to brownish papules and spread to the outer side of chest. The lesions became itchy. There was no underline disease.

\section{Figure 1}

Figures 1, 2: Papules on the right side of the chest

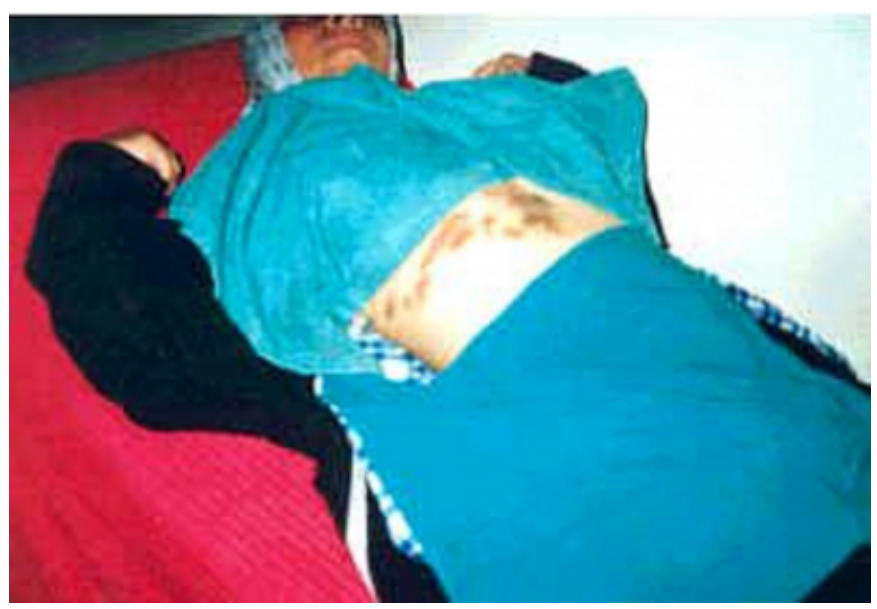

\section{Figure 2}

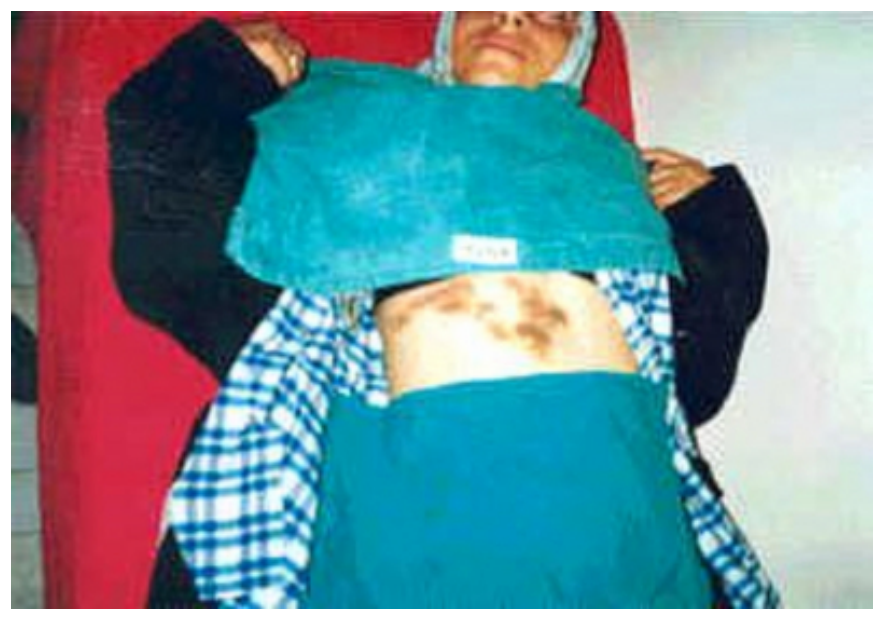

The initial diagnosis was epidermal nevus, wart, localized Darier,s Disease. A biopsy was performed and the histology showed hyperkeratosis and achantosis with basaloid appearance and true and pseudo horn cysts in the epidermis and chronic inflammatory reaction in dermis (Fig. 3,4). 


\section{Figure 3}

Figure 3: Hyperkeratosis, achantosis, horn cysts

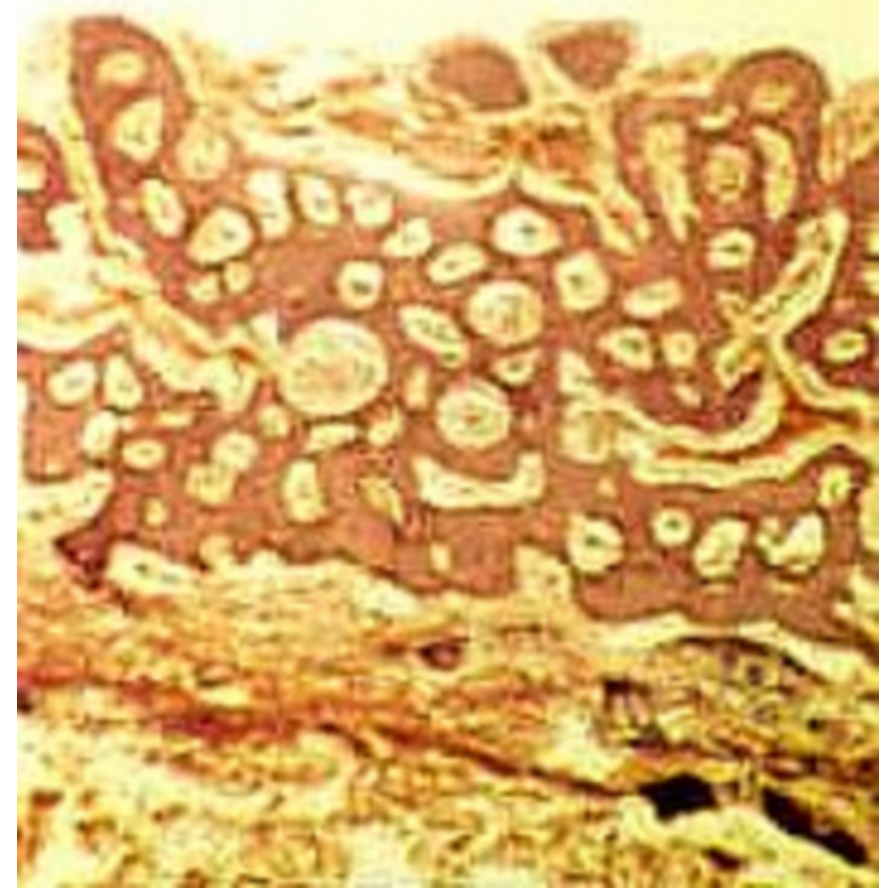

\section{Figure 4}

Figure 4: True and psudo cysts

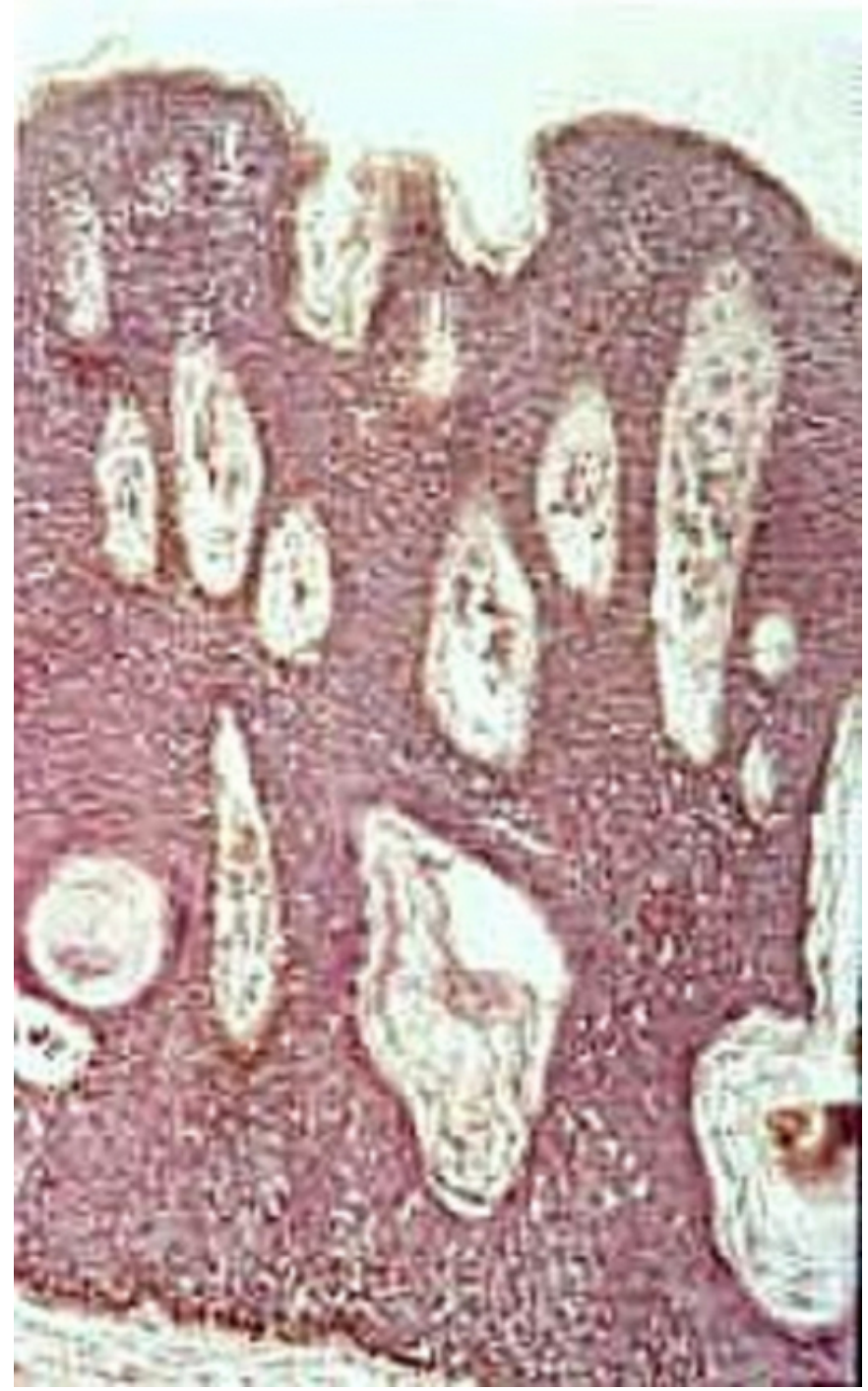

DISCUSSION

Seborrhea Keratosis is a benign skin tumor which develops from the proliferation of keratinocytes of the epidermis.$(1,2)$ This dermatosis is less common in populations with dark skin compared to those having white skin, and a sex difference does not appear to occur in the frequency of occurrence of Seborrheic Keratosis.(1)

The lesions appear to increase with age. In one study of 70 candidates aged 15-30 years with white skin, increase in frequency was noted from $15.7 \%$ in people aged 15-19 years to $23.3 \%$ in people aged $25-30$ years. $\left({ }_{3}\right)$

The lesions have a variety of clinical appearances and vary from macular form to papules and plaques with rough texture and waxy yellowish to dark brownish scaly surface.(1) The lesions usually are asymptomatic, but can be 
itchy. $(1,2)$ The lesions tend to be self limited and the appearance of new lesions may continue for a few years.(2) There is no report of malignant changes. Seborrheic Keratosis can occur on almost any site of the body, with the exception of the palms and soles. $\left(1,{ }_{4}\right)$ Its areas of predilection are the face and trunk. The appearance on both areola is reported.(.) One patient has been described of having multiple fibroepithelial basal cell carcinomas associated with Seborrheic Keratosis distributed in a neviform fashion on the left side of the body. $\left(_{6}\right)$ There is one report of distribution along skin cleavage lines on the lower back and waist of a 65-year-old woman. ${ }_{7}$ ) Raindrop pattern on the back of elderly patients has been described. $\left({ }_{8}\right)$ But dermatomal distribution without underlying disease, like our patient has not been reported previously and this type may be a new variant of Seborrheic Keratosis.

\section{CORRESPONDENCE TO}

Afshar Ramezanpour MD., Department of Dermatology, Razi Hospital ,Gilan, IRAN, +98,(0)131,5550028; EMail: drafsharpr@yahoo.com

\section{References}

1. ARNDT, cutaneous medicine and surgery, 1996; vol 2:1444-8

2. ROOK, Textbook of Dermtology, 1998;vol 2:1658-1660

3. Gill D MBBS,Dorevitch Abe MD,Marks R MBBS,MPH;

The prevalence of seborrheic keratosis in people aged 15-30 years, Arch Dermatology. 2000;136(6):756-762

4. ANDREW'S, Disease of the skin, 2000;804-6

5. Trattner A, David M, Sand bank M; Seborrheic Keratosis of the areola. cutis, 1994;Feb:53(2):95-6

6. RODRIGUEZ ra, Festa Netoc; Multiple fibroepithelial B.C.C. of pincus assosiated Seborrheic Keratosis in a nevoid distribution. j Dermatol, 2000;May 27(5):341-5

7. Li X, Zhu W;A case of seborrheic kerayosis distributed along skin cleavage lines. J Dermatol, 1998,Apr 25(4):272-4 8. P Hefferan MD, A Khavari MD,PHD; Raindrop seborrheic keratosis, A distribution pattern on the back of elderly patient. Arch Dermatol, 1998; Mar 134(3):382-3 


\section{Author Information}

Abbas Darjani, Clinical Assistant Professor

dermatology, Razi Hospital, Medical University

Afshar Ramezanpour, Resident

Dermatology, Razi Hospital, Medical University 